\title{
International Journal of Engineering
}

\author{
Journal Ho me page: w w w. i je.i r
}

\section{Optimization of Control System of Petroleum Refinery Isomerization Unit by Plant- Wide Control Principles}

\author{
A. R. Fazlali*, V. Ghaleh Khondabi, J. Tavakoli, M. Mahrouei \\ Department of Chemical Engineering, Faculty of Engineering, ArakUniversity, Arak, Iran
}

\section{$P A P E R I N F O$}

\section{Paperhistory:}

Received 17 March 2018

Received in revised form 07 March 2019

Accepted 03 May 2019

\section{Keywords:}

Dynamic Simulation

Isomerization

Optimization

Plant-wide Process Control

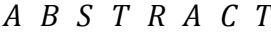

Industrial process control system due to int egration of equipment, existing material and energy recycle streams and their effects are extraordinary importance. The process in terms of safety, product quality and control stability have a challenge when there was defects in a process control system. The isomerization process is gaining importance in the presence of refining context due to upgrading the octane number of light naphtha fractions and also simultaneously reduces aromatic compounds especially benzene content. In this study, the isomerization unit control system of Imam KhomeiniOil Refinery Company (IKORC, shazand, Iran), by defined four controllers include: the temperature controller on pre-heater exchanger, the concentration controller on depentanizer, deisopentanizer and deisohexanizer towers. This work is based on the nine principles of the plant-wide process control, was investigated. It should be noted that currently lack these four controllers in isomerization unit, confront this unit to challenge in dealing with sudden disturbances. The results show that obtained data from dynamic simulation by Aspen Hysys v7.3 had an acceptable compliance with the principles of plantwide process control theory.

doi: $10.5829 /$ ije.2019.32.07a.01

\section{INTRODUCTION}

Isomerization of normal alkanes into their corresponding branched isomers with high octane number, low sensitivity (the difference between research octane number (RON) and motor octane number (MON)), and low sulfur content, is an important petroleum refining process. Isomerate can burn easily and cleanly; it is a good blending component for clean motor gasoline [1]. Isomerization was developed during World War II to produce iso-butane necessary for the manufacture of alkylates, which are used as blend stocks in high-octane aviation gasoline. Today isomerization is mainly focused on upgrading of refinery naphtha streams into highoctane motor gasoline [2]. Naphtha and reformate are complex mixtures of paraffin's, naphthenes, and aromatic in the range of naphtha compositions $\left(\mathrm{C}_{5}-\mathrm{C}_{12}\right)$ $[3,4]$. Is omerization of light naphtha streams rich in $\mathrm{C}_{5}$ and $\mathrm{C}_{6 \text { s }}$ typically results in an increase of 10-20 octane numbers [5].
The isomerization unit consists of a complex flow diagram and many different equipment in a wide range of operating conditions. The existence of multiple recycle streams, energy integration and sequential arrangement of the various equipment makes it easy to transfer disturbances from the upstream units to the downstream units [6]. Therefore, due to the complexity of the process and the effect of the control loops of this unit on each other, we must adopt control measures and use appropriate tools for safe operation and achievement of design goals.

Over a period of time, a variety of methodes have been developed by scientists and designers to optimize process control. Buckely [7] the pioneer of the process control field, and for the first time the theory of separation of process control issues as parts, viz., the control of material balance and the quality control of products was proposed. Foss [8] stated on the gap between theory and practice in the area of process control. A similar observation that applications seem to

*Corresponding Author Email: a-fazlali@araku.ac.ir (A. R. Fazlali) 
be ahead of formal theory was made by Findeisen et al. [9] in their book on hierarchical systems. Stephanopoulos [10] stated that the synthesis of a control system for a chemical plant is still to a large extent an art. Douglas [11] devised a gradual approach to conceptual design in the process chart and expanded control concepts. Balchen and Mumme [12] attempt to combine process and control knowledge to design control systems for some common unit operations and also consider plant-wide control.

Rijnsdorp [13] identified differences between two situations, maximize production and produce a given amount at lowest possible cost. He also has a procedure for design of an optimizing control system. Rinard and Downs [14] referred to the control structure design problem as the strict definition of plant-wide control, and they pointed out that plant-wide control also included important is sues such as the operator interaction, startup, grade-change, shut-down, fault detecion, performance monitoring and design of safety and interlock systems. Van de Wal and de Jager [15] listed out several criteria for evaluation of control structure design methods. $\mathrm{Ng}$ and Stephanopoulos [16] applied almost exclusively with plant-wide control. Skogestad [17] discussed on controlability analysis, and on control structure design related to partial control and self-optimizing control.

Downs [18] found that the balance of chemical components around the starting point for the entire process and equipment must be checked and that it should be ensured that all components (reactants, products and neutral materials) have a way of exiting or are consumed inside the process. Luyben et al.[19] put forward a theory called plant-wide process control. This theory consists of 9 steps in which the essential variables of the process were identified and proposed for controlling them. In order to determine the best controller for a variable, it is necessary that the performance of each controller is checked for the process and ultimately, the most accurate one. The plant-wide process control theory was first implemented on the hydrodealkylation of toluene (HAD) process and its satisfactory results led to the use of this theory to design a control system for many processes [20].

In this work, the plant-wide process controlsystemof IKORC (Shazand, Iran) isomerization unit has been studied. To achieve this aim, first, the process was dynamically simulated by Aspen Hysys v7.3, and then nine step of the plant-wide process control theory has been implemented on this model to achieve an acceptable control system.

\section{DYNAMIC SIMULATION}

2. 1. Isomerization Process Description The light naphtha (C5-C6) isomerization process generally consists of two parts of the reaction section and the separation section [21]. In the first section, the material flows initially enter the pre-heat exchanger and then enters plug flow reactor, which includes the main reactions: is omerization of $n$-pentane and $n$-hexane, and saturation of aromatic compounds, especially benzene, and secondary reactions such as hydrocracking. In the second section, the iso-pentane product from top of the deisopentanizer tower and the iso-hexane product from top and bottom of the deisohexanizer tower are mixed and sent to refinery tanks as a isomerate product.

In IKORC (Shazand, Iran) isomerization unit (Figure 1) [22], the operating conditions are given in Table 1. The three recycle stream loops that exist in the unit include: circulating gas recycle stream, n-pentane and n-hexane recycle streams. Naturally, higher the number of recycle streams, more challenging will be with respect to the process. If a disturbance occurs in recycle stream, at one cycle process, this disturbance intensifies and becomes larger. This trend continues over time as the system goes out of control.

2. 2. Process Control Modeling To design or review the control system of an industrial process, it needs a dynamic model of that process. So, the isomerization process simulated by Aspen Hysys v7.3 with dynamic model, which is expressed in nine steps:

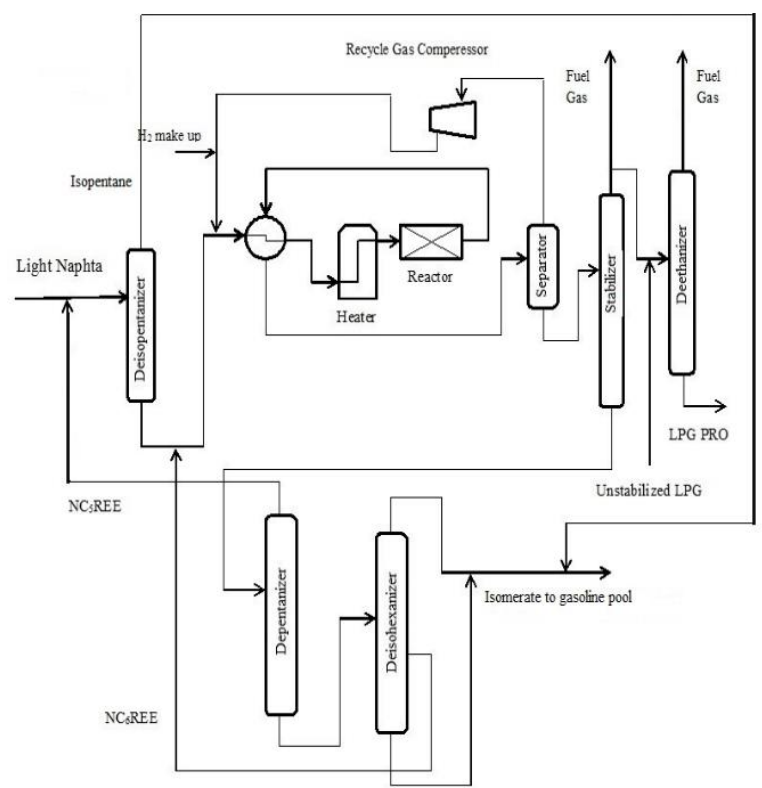

Figure 1. The light naphtha isomerization unit flow diagram

TABLE 1. Operating conditions of the isomerization process in the presence of zeolite catalyst

\begin{tabular}{|c|c|c|c|c|}
\hline $\begin{array}{l}\text { Process } \\
\text { Parameters }\end{array}$ & $\begin{array}{c}\text { Temperature } \\
\left({ }^{\circ} \mathbf{C}\right)\end{array}$ & $\begin{array}{c}\text { Pressure } \\
\text { (barg) }\end{array}$ & $\begin{array}{c}\mathbf{L H S V}^{*} \\
\left(\mathbf{h} \mathbf{r}^{-1}\right)\end{array}$ & $\mathrm{H}_{2} / \mathbf{H C}$ \\
\hline Amount & $220-280$ & $15-35$ & $1-3$ & $1-2$ \\
\hline
\end{tabular}


Step 1: Determine the objectives of the control system In this step, the important parameters of the process were identified. Level of vessels, flow rate of feed stream, downstream flow of deisopentanizer tower, recycle streams of n-pentane and $n$-hexane, inlet gas stream into reactor, furnace and reactor inlet temperature and pressure vessel, can be considered as the most important operational variables in the isomerization process.

Step 2: Find the freedom degrees of control system

The number of degrees of freedom is the number of variables that are controlled by giving the adjustment point. According to the first step and the examination of controlled variables, there are 18 degrees of freedom.

Step 3: Create an energy management system

The main purpose of creating an energy management system is to use cold and hot streams and to prevent the sudden increase or decrease in temperature of the influential flows inside the process. In the isomerization process, the reaction section and especially the pre-heater exchangers should be studied in terms of cold and hot streams. It is usually recommended to create a bypass stream to control the temperature fluctuations around the furnace, reactor and pre-heater exchanger loop.

Steps 4 and 5: Setting the rate and quality of the products

Temperature is the only variable in the reactor, which can affect the rate and quality of products. The inlet temperature of the reactor is controlled by the amount of fuel in the furnace. Increasing the temperature of the is omerization reactor with a hysopare catalyst up to $50^{\circ} \mathrm{C}$ is allowed. In this case, it can be assured that the rate and quality of the products are controlled.

Step 6: Constanting the flow in recycle stream loop

The recycle stream of $n$-pentane, separated from top of the depentanizer tower, as well as the recycle stream of $n$-hexane, separated from middle of the deis ohexanizer tower, was fixed by flow controllers to avoid disturbances caused by them.

Step 7, 8 and 9: Check the balance of compounds, separate control of an equipment, and dynamic control optimization

The seventh and ninth steps are overview, but in step eight, it is discussed with the choice of controllers that are necessary to control an equipment. The remaining variables in step one, which the controller selection for them depend on the dynamic analysis, are analyzed in step eight.

\section{RESULTS AND DISCUSSION}

\section{1. The Temperature Controller On Pre-Heater} Exchanger One of the problems of the isomerization unit control system of IKORC (Shazand, Iran) is the reactor temperature disturbances, which sometimes greatly increases the reactor output temperature and this is while the control strategy are not considered. Of course, this extreme temperature fluctuation, dis rupts the reactor's performance due to the loss of catalyst activity and damage to the reactor body, as well as the quality of the isomerate product, which is not economically feasible for the refinery.

In Figure 2, an intense fluctuation in loop of furnace, reactor and pre-heater exchanger has been made that the effect of this fluctuation on the outlet temperature of reactor and pre-heater exchanger is quite obvious. In Figures 3 and 4, the effect of the temperature fluctuation on the reactor output products and their octane number is given. To prevent temperature fluctuations in the reactor, a by-pass stream for the pre-heater exchanger (E$3304 \mathrm{~A} / \mathrm{B} / \mathrm{C} / \mathrm{D})$ of furnace is embedded.

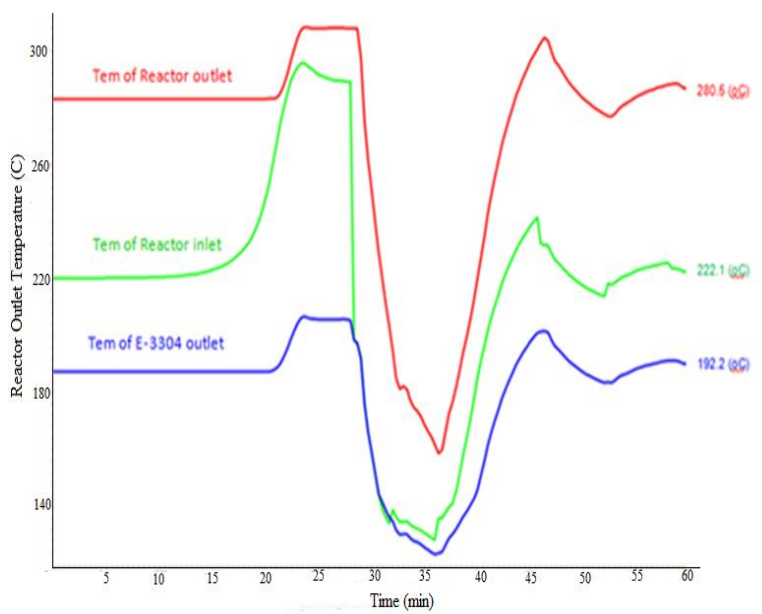

Figure 2. Fluctuation in loop of furnace, reactor and preheater exchanger

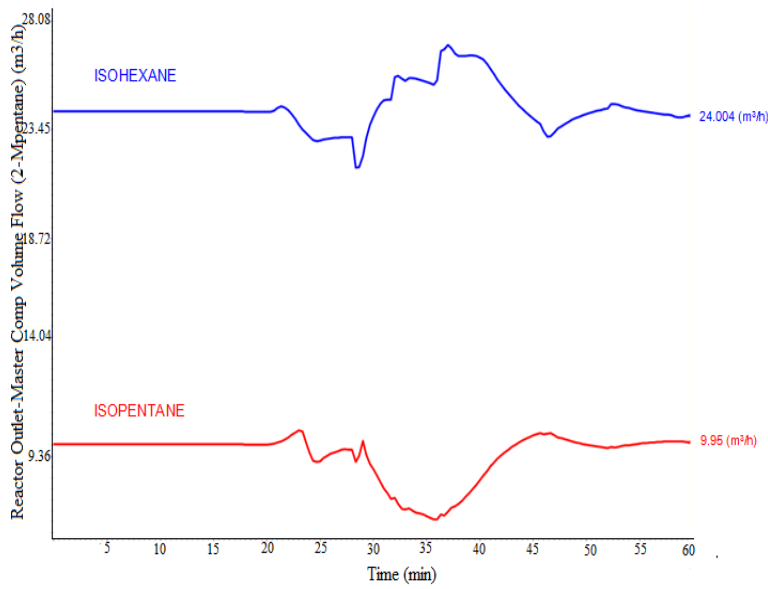

Figure 3. The effect of reactor temperature fluctuation on the rate of iso-pentane and iso-hexane as the reactor main products 


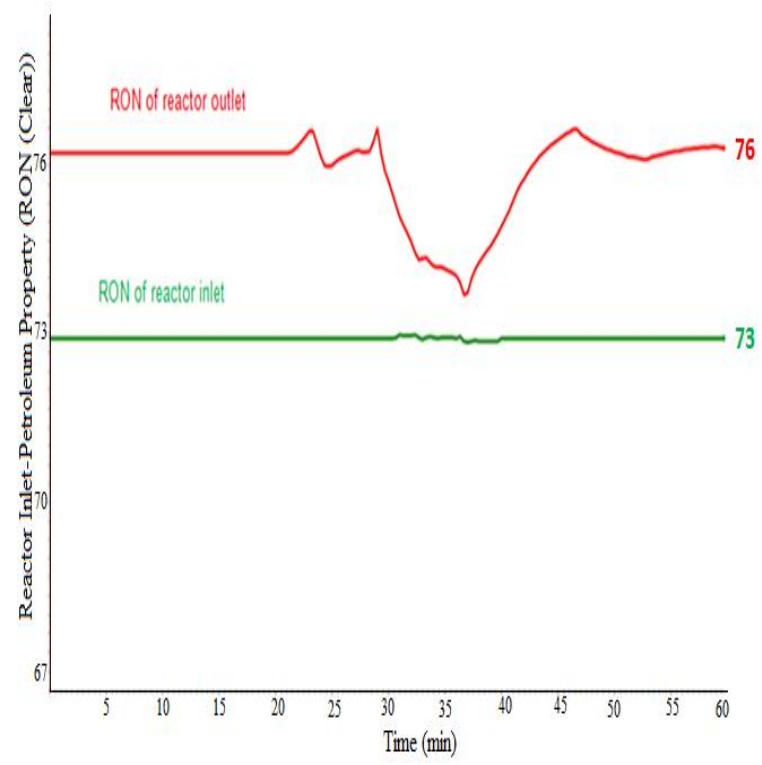

Figure 4. The effect of rector temperature fluctuation on the rector output octane number

\section{2. The Concentration Controller On Towers} Another problem with the isomerization unit control system is the lack of a concentration analyzer for the important unit (deisopentanizer, depentanizer and deisohexanizer towers) is used, which can greatly affect the quality of the product in unfavorable conditions.

\section{2. 1. Deisopentanizer Tower The stream that} is separated from the top of the deisopentanizer tower is sent out to the outside of the unit, and it consists mainly of is o-pentane with a concentration of $99.6 \%$. Fluctuating in the concentration of iso-pentane can lower the isomeriate product quality. Therefore, in order to maintain this concentration, an analyzer should be installed at the top of the tower.

Should define a control strategy for a concentration analyzer that would not change the iso-pentane concentrations of top of the tower, when the tower conditions change. There are several variables in the tower that can be controlled by the analyzer controller, in which the temperature of bottom of the tower and the pressure of top of the tower are the most common variables. By checking the variables in the tower, it was determined that if the analyzer's concentration decreases, the temperature of bottom of the tower should be increased (Figure 5) and the pressure of top of the tower should be reduced (Figure 6). Therefore, there is no significant decrease in the concentration analyzer. Typically in industrial processes, the temperature of bottom of the tower is used as a variable for controlling the concentration analyzer. This control strategy for V3301 is given in Figure 7.

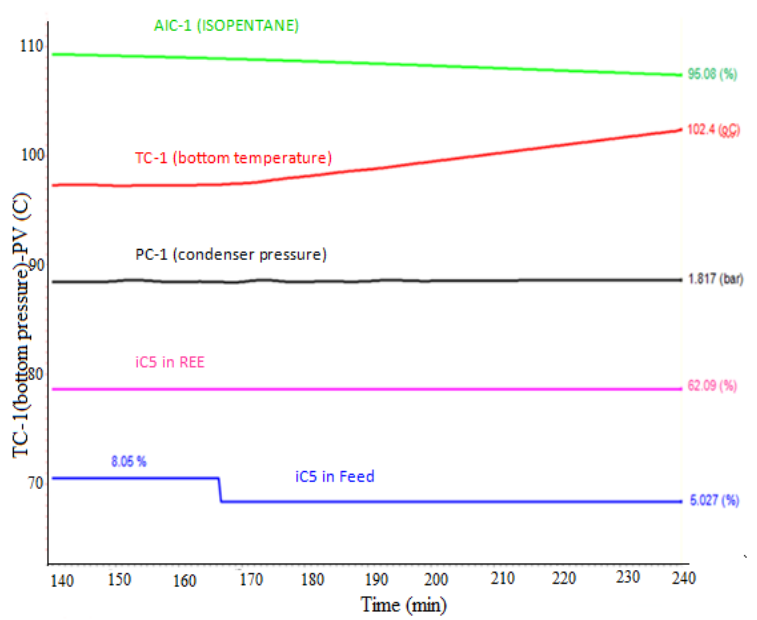

Figure 5. Controlling of the iso-pentane concentration analy zer of deisopentanizer tower by temperature of bottom of tower

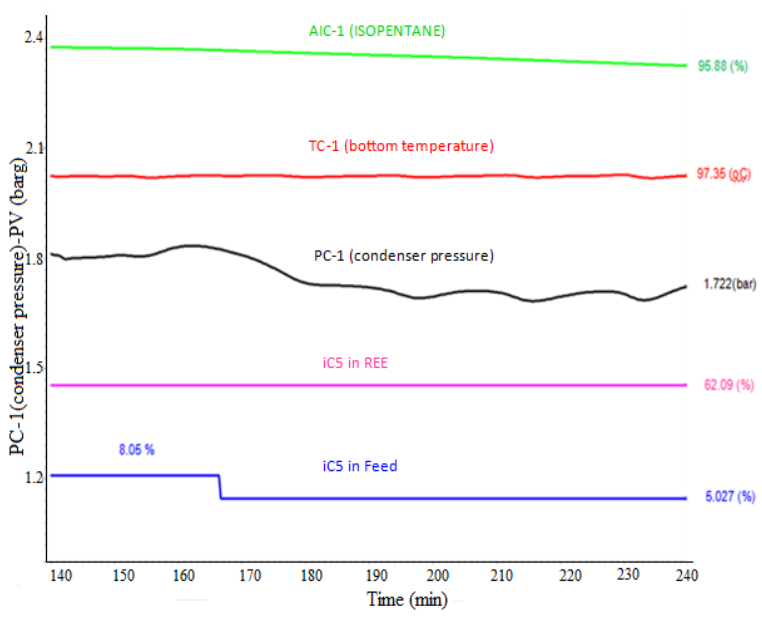

Figure 6. Controlling of the iso-pentane concentration analyzer of deisopentanizer tower by pressure of top of tower

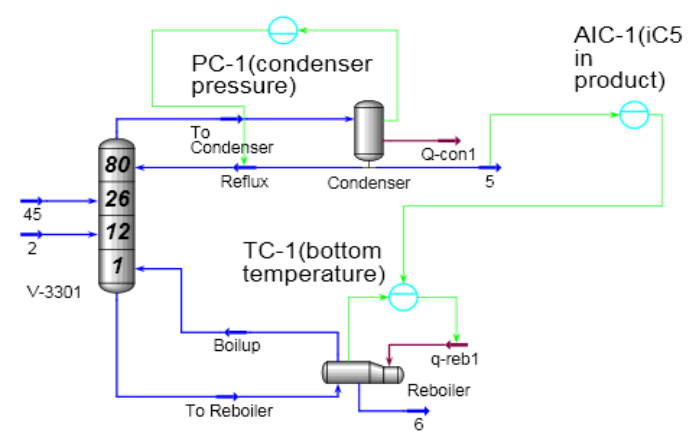

Figure 7. Controlling of the iso-pentane concentration analyzer by temperature of bottom of tower 
3. 2. 2. Depentanizer Tower A discharged stream from top of the depentanizer tower is fed as a n-pentane recycle stream to the V-3301. The normal state of $n-$ pentane concentration at the top of the depentanizer tower is $36.6 \%$. Figure 8 shows the control of the $n$ pentane concentration of the top of tower by the heat rate of reboiler in terms of changing the inlet $n$-pentane concentration of the tower. Figure 9 demonestrates its control strategy.

\section{2. 3. Deisohexanizer Tower The streams of top} and bottom of the deisohexanizer tower as products are mixed with isomerate of the deisopentanizer and leave the unit. Therefore, the definition of the iso-hexane

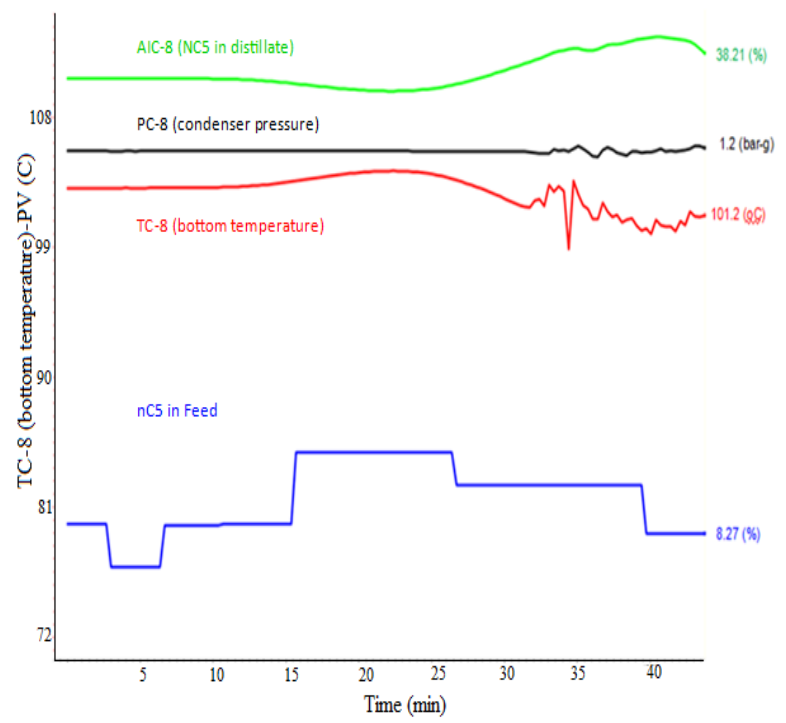

Figure 8. Controlling of the n-pentane concentration of top of tower by temperature of bottom of tower

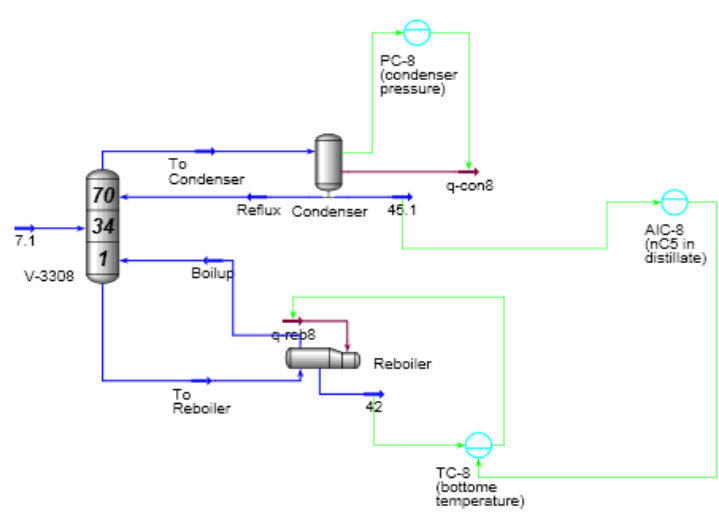

Figure 9. Control strategy of n-pentane concentration analyzer concentration analyzer for V-3310 can play a significant role in controlling the quality of the isomerate product. Figure 10 shows the control of the iso-hexane concentrations of top of the tower by the heat rate reboiler in the conditions of the change in the inlet iso-hexane concentration of the tower and Figure 11 illustrates its control strategy.

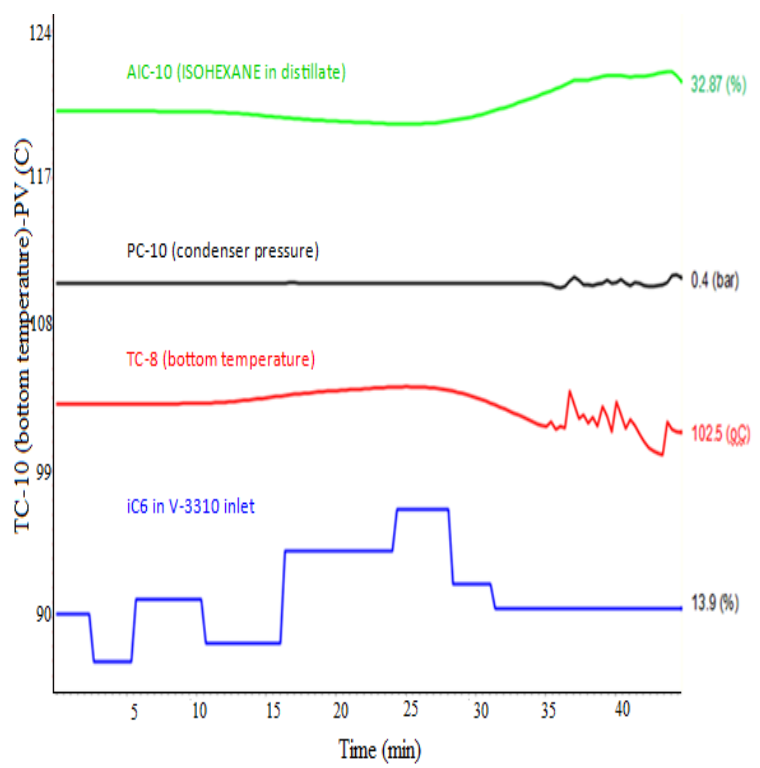

Figure 10. Controlling of the iso-hexane concentration of top of tower by temperature of bottom of tower

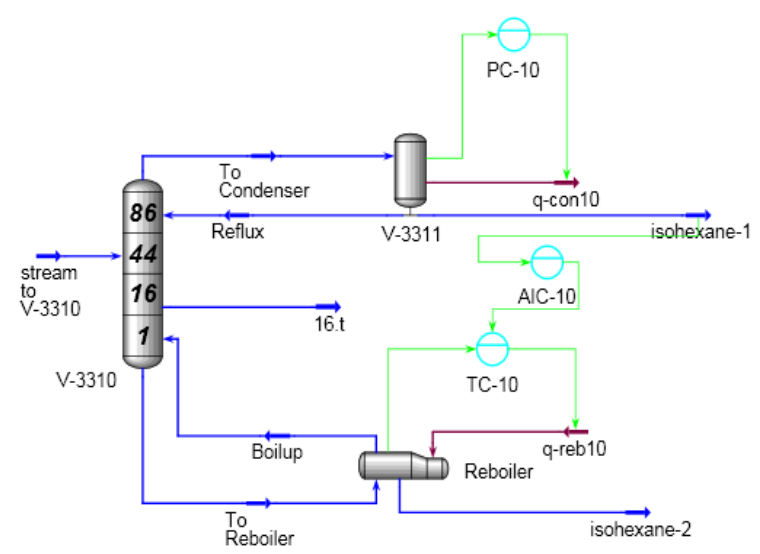

Figure 11. Control strategy of iso-hexane concentration analyzer in deisohexanizer tower

\section{CONCLUSION}

Isomerization complements catalytic reforming process is an upgrading the octane number of refinery naphtha streams. Isomerization is also a simple and cost-effective 
process for octane enhancement compared with other octane-improving processes. Is omerate product contains very low sulfur and benzene, making it ideal blending component in refinery gasoline pool. Due to the significance of isomerization in the modern refining industry, it becomes essential to optimize its control process. The results of the implementation of the plantwide process control theory on the model of IKORC (Shazand, Iran) refinery isomerization unit are included: $\checkmark \quad$ The existing control system conformed to the plant-wide process control principles and the performance of the controllers of this system did not interfere with each other.

$\checkmark \quad$ In the existing control system, the surface of any vessel did not fluctuate significantly and in the V-3309 and V-3312, although the inlet flow has fluctuated and their output were constant as the recycle flow, the surfaces reached to the adjustment point and became stable.

$\checkmark \quad$ Using dynamic simulation by Aspen Hysys v7.3, to have more efficient control system, two suggestions are proposed:

Creating a temperature controller on the by pass stream of the pre-heater exchanger of furnace is essential to prevent possible temperature fluctuations (which damages the catalysts) in the loop of furnace, reactor and pre-heater exchanger.

$>\quad$ Creating a concentration controller on top of the depentanizer, deisopentanizer and disohexanizer towers, in addition to avoiding the process from extreme fluctuations, is also a step towards guaranteeing the quality of the is omerate product.

\section{REFERENCES}

1. Hancsok, J., Magyar, S., Szoboszlai, Z. and Kallo, D., "Investigation of energy and feedstock saving production of gasoline blending components free of benzene", Fuel Processing Technology, Vol. 88, No. 4, (2007), 393-399.

2. Newalkar, B.L., Nettem, V.C. and Siddiqui, M.A., "Hydroisomerization catalysts: Chemistry and its features. Catalysts in Hydrocarbon Processing \& Fertilizer Industry", Petrotech Society, New Delhi, India, (2005).

3. Askari, A., Karimi, H., Rahimi, M.R. and Ghanbari, M. "Simulation and modeling of catalytic reforming process", Petroleum \& Coal journal, Vol. 54, No. 1, (2012), 76-84.
4. Rahimpour, M.R., Jafari, M. and Iranshahi, D., "Progress in catalytic naphtha reforming process: A review", Applied Energy, Vol. 109, (2013), 79-93.

5. Weyda, H. and Kohler, E., "Modern refining concepts: An update on naphtha isomerization to modern gasoline manufacture", Catalysis Today, Vol. 81, No. 1, (2003), 51-55.

6. Rangaiah, G.P. and Kariwala, V., "Plant-wide Control: Recent Developments and Applications”, Wiley Interscience, (2012).

7. Buckley, P.S., "T echniques of process control", John Wiley \& Sons Ltd, New York, USA, (1965).

8. Foss, A.S., "Critique of chemical process control theory", $\boldsymbol{A I C h E}$ Journal, Vol. 19, No. 2, (1973), 209-214.

9. Findeisen, W., Bailey, F.N., Brdys, M., Malinowski, K., Tatjewski, P. and Wozniak, A., "Control and coordination in Hierarchical Systems”, John Wiley \& Sons Ltd, New York, USA, (1980).

10. Stephanopoulos, G., "Synthesis of control systems for chemical plants: A challenge for creativity", Computers \& Chemical Engineering, Vol. 7, No. 4, (1983), 331-365.

11. Douglas, J.M., "Conceptual Design of Chemical Processes", McGraw-Hill Publishing Co, USA, (1988).

12. Balchen, J.G. and Mumme, K.I., "Process Control: Structures and applications", Van Nostrand Reinhold, New York, USA, (1988).

13. Rijnsdorp, J.E., "Integrated Process Control and automation", Elsevier, (1991).

14. Rinard, I.H. and Downs, J.J., "Plant-wide control: A review and critique", AIChE Spring Meeting, New Orleans, USA, (1992).

15. Van De Wal, M. and De Jager, B., "Control structure design: A survey", Proceedings of the American control conference, Seattle, USA, (1995).

16. Christine, N. and Stephanopoulos, G., "Plant-wide control structures and strategies", IFAC Journal of Systems and Control, Vol. 31, No. 11, (1998), 1-16.

17. Skogestad, S., "Plant-wide control: The search for the selfopt imizing control structure", Journal of Process Control, Vol. 10, No. 5, (2000), 487-507.

18. Downs, J.J., "Distillation Control in a Plant-wide Control Environment", Van Nostrand Reinhold. Springer, Boston, USA, (1992).

19. Luyben, W.L., Tyreus, B.D. and Luyben, M.L., "Plant-wide process control", McGraw-Hill Publishing Co, USA, (1998).

20. Luyben, W.L., "Plant-wide Dynamic Simulators in Chemical Processing and Control", CRC Press, $1^{\text {st }}$ edition, (2002).

21. Graeme, S. and Van Der Laan, M., "Butane and light naphtha isomerization", Petroleum Technology Quarterly, Vol. 8, (2003), 47-49.

22. National Iranian Oil Engineering \& Construction Co (NIOEC), "Basis of design for isomerization unit (Unit-No.33 ISOM))", Arak Refinery Expansion and Products Upgrading Project, (2004). 


\section{Optimization of Control System of Petroleum Refinery Isomerization Unit by Plant- Wide Control Principles}

A. R. Fazlali, V. Ghaleh Khondabi, J. Tavakoli, M. Mahrouei

Department of Chemical Engineering, Faculty of Engineering, Arak University, Arak, Iran

\section{PAPER INFO}

Paper history:

Received 17 March 2018

Received in revised form 07 March 2019

Accepted 03 May 2019

\section{Keywords:}

Dynamic Simulation

Isomerization

Optimization

Plant-wide Process Control

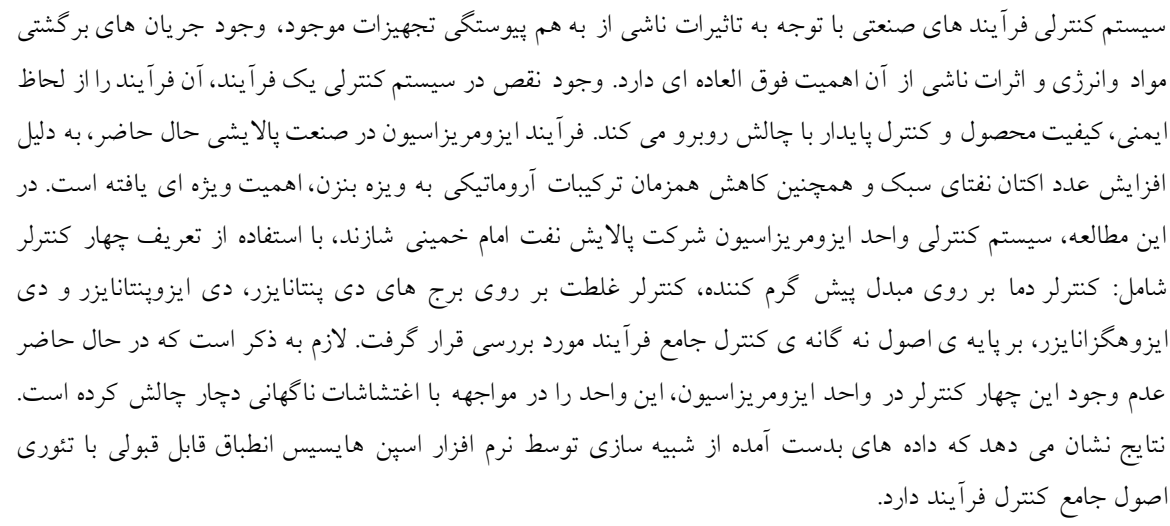

